\title{
Focus Point on the Transition to Sustainable Energy Systems
}

\author{
Published online: 28 February 2018 - (C) Società Italiana di Fisica / Springer-Verlag 2018
}

The "Energy Transition", as it is often called, i.e. the replacement of all present energy sources by low carbon energy sources, has been put forward by the European Union, and the countries participating in the Paris 2015 Climate Conference (COP-21), as an effective means to cutting fossil fuels consumption and $\mathrm{CO}_{2}$ emissions. Given the important role of fossil fuels for the world economy, this is a major challenge for the 21st century.

Fossil fuels have been the motor behind an unprecedented growth in the quality of life and freed developed countries from the vagaries of the weather over, at least, the last 150 years. Their contribution to the primary energy supply of this world is now close to $85 \%$, stagnating or even slowly growing. It is very difficult to quantify the precise role of $\mathrm{CO}_{2}$ and other greenhouse gases in our changing climate as exemplified by recent findings [1].

The EU Energy Roadmap 2050 focuses on reducing $\mathrm{CO}_{2}$ production in the EU power sector. The limited (and sometimes harmful) potential of dispatchable renewable electricity sources (biofuels, hydropower, etc.) causes solar and wind power to dominate renewable electricity production in most cases. Their intermittency, however, strongly reduces their efficiency and imposes a large storage or non-renewable backup system (thus unavoidably fossil or nuclear). Storage of excess electricity production by intermittent renewables at the level required needs a substantial amount of research; if, then, also nuclear is banned for electricity production, one will be forced to continue using fossil fuels in order to guarantee a secured electricity supply, in contrast to the original aims of EU Energy Roadmap 2050. Thus questions, like on what time scale we should completely shut down the $\mathrm{CO}_{2}$ output of the current EU electricity production, at what cost and what kind of system should replace it, while maintaining and further expanding comfort and well-being in an affordable way to all EU citizens, need to be answered very cautiously.

This Focus Point tries to answer a few central questions regarding the planned Energy Transition, with focus on Europe's power sector. An important example is the German Energiewende, one of the largest and costliest energy experiments on Earth, and the most developed worked-out example of what the EU Commission essentially proposes for all EU countries in its Energy Roadmap 2050.

It is hoped that this set of papers can get the widest possible distribution, in order to provide colleagues all over Europe with very important first-hand information, and to contribute to a rational debate about a determining factor for the future of our children and grandchildren.

\section{References}

1. Richard J. Millar et al., Nat. Geosci. 10, 741 (2017). 